\title{
Stage I Small Intestinal Cancer AJCC v7
}

National Cancer Institute

\section{Source}

National Cancer Institute. Stage I Small Intestinal Cancer AJCC v7. NCI Thesaurus. Code C5807.

Stage I includes: (T1, N0, M0); (T2, N0, M0). T1: Tumor invades lamina propria or submucosa. T2: Tumor invades muscularis propria. N0: No regional lymph node metastasis. M0: No distant metastasis. (AJCC 7th ed.) 